\title{
Voice Based Employee Management System Using AWS and Alexa
}

\author{
Ritika Punia, Shubham Panwar, Ruchi Kamra, Rashmi Gupta
}

\begin{abstract}
In the developing and creating world, everything is getting advanced, digital, computerized, and automated. With an oversized number of labor opportunities, the Human workforce has increased. Thus, there is a need for a system that can handle the information of such a large number of employees in a company. This project untangles the task of maintaining records and data of employees, thanks to its user-friendly GUI. The "EMPLOYEE MANAGEMENT SYSTEM using AWS" has been created to abrogate the issues with the existing manual framework. This application is designed in such a simplest way that it can eliminate and in some cases reduce the efforts faced by the live system. Moreover, this method is meant for the actual need of the corporate to holdout operations smoothly and effectively. A Voice command feature is additionally added to the system to avoid a waste of time. The application is coded in such a way that, it avoids mistakes while entering the data. It notifies the employee/admin if he entered the incorrect, or invalid data. No formal knowledge or special training is required by the employee/admin to use this application. Thus, it is approved as an easy to understand and person-friendly utility. The Voice command feature is additionally straightforward to use and informative. This project will allow admin to feature new employees after proper authentication (manual). Admin can even edit departments and posts (in a variety of bands). The database should store all personal details of employees like date of birth, full name, people, address, etc. this method enables employees to fill their time-sheets daily or at intervals. The admin can approve or reject the time-sheet filled by a worker together with remarks. Admin may make workdays, Performance charts, Leave details, and will edit employee details. An employee can access its details using Alexa.
\end{abstract}

\section{Manuscript received May 22, 2020}

Ritika Punia, Department of Computer Science \& Engineering, Amity University, Haryana, Gurgaon, India (email: ritika1punia@gmail.com)

Shubham Panwar, Department of Computer Science \& Engineering, Amity University, Haryana, Gurgaon, India.

Ruchi Kamra, Assistant Professor Department of Computer Science \& Engineering, Amity University Gurgaon, Haryana, India

Rashmi Gupta, Assistant Professor, Department of Computer Science \& Engineering, Amity University Haryana, Gurgaon, India.
KEYWORDS- Employee Management system, EMS AWS, Leave Monitor, Amazon Web Services.

\section{INTRODUCTION}

The "Employee Management System using AWS" is one of the foremost innovative means of monitoring employees and employee hierarchy along with the daily work done by the employees. It operates on AWS which is one of the most scalable and affordable technologies available for a medium-scale business that aspires to go completely online. Employee Management System (EMS) using AWS refers to the processing of information through their dashboard with role-based access for employees at different hierarchical levels to manage and support managerial decisions within an organization. The project allows the administrator to create the work schedules for the entire year and keep a check on the work done by all other employees each day while keeping track of their leaves and their managers. The Employee Management System using AWS brings artificial intelligence in the process of keeping track of the employees and their details without having to log in to their administrator dashboard, just by asking Alexa (Amazon's Artificial Intelligence). Various managers within an organization can take access (different levels) to the system and know the status of reports concerned with their department without the need of going to the IT Department and checking the status manually by raising a ticket. It operates on PHP which is one of the best languages to use for Web Development as it is Open Source, extensible, and compatible with servers like IIS and Apache. It is supported by Bootstrap for its efficient design. Since the Employee Management System using AWS is built using the bootstrap framework, it is mobile friendly and can be accessed through any mobile device. Employee Management System using AWS relies on Relational Database (RDS - AWS) and MySQL for access to the databases. Each employee on the Employee Management System using AWS has an existence in the MySQL database which has the record of the time of the day when the employee has been added, the days they worked, what they worked on, and who they report to. Employee Management System (EMS) using AWS refers to the processing of information through their dashboard with role-based access for employees at different hierarchical levels to manage and support managerial decisions within an organization. The project allows the admin to create the work schedules for the entire year and keep a check on the work done by all other employees each day while keeping 
track of their leaves and their managers. This system is used by employers to increase the productivity and efficiency of all their employees.

The main Objectives of the proposed application is:-

- Automate the process of employee tracking and performance.

Employers can check the number of hours an employee was in the office on what day, the work they did that day, and who they report to. Employers can create the entire planner of workdays and leaves for their company, hence predicting the work output and analyzing their goals for the year.

- Fast, Easy, and reliable.

Data of employees in the application is accurate, precise, reliable, and secure using AWS services. The processing time is fast as compared to other systems. The system is easy to use as the console display is the same for each level of users and easy use of Alexa makes it flexible to use for everyone.

The proposed application is made using Amazon's Virtual Assistant Alexa, Amazon Web Services, Apache Server, Putty, Alexa skill kit, Mysql workbench, Sublime. The Languages used are HTML, CSS3, Bootstrap, Javascript, PHP.

\section{LITERATURE REVIEW}

A lot of research in different fields related to this topic has been done. Previously the employer had to manually ask the managers to give the report of all the employees under their management. This would leave a lot of room for excuses, and human error. The work hours of the employees weren't being digitally stored and had to be checked manually. This process was time-consuming and inefficient as there was a dependency on managers for accessing the status of employees. There was no digital record of the number of leaves each employee had taken, or the upcoming compulsory leaves which would hinder the working of the office. Kancho Dimitrov Kanchev proposed a EMS using Access Database Environment as a Database Management System and C\# as a programming language for developing the project. He stated that the choice of programming language on which an developer need to develop the application can differ but the database and the functions of the application will remain same[1].Another EMS is also developed using php,xampp, Mysql and HTML. At front end they have used 'HTML' and 'CSS', at the back-end they have used 'php', scripting languages used are 'java-script' and 'AJAX' and for database we have used MySQL.[2]One more EMS has been developed by an organization. This software project has been developed using the powerful coding tools of HTML, CSS and PHP at Front End and Microsoft Sql Server at Back End. The software is very user friendly [3].Mweemba Simaanya also developed a program to manage employees in an organization. A HRMS refers to the systems and processes at the intersection between human resource management (HRM) and information technology. It merges HRM as a discipline and in particular it's basic HR activities and processes with the information technology field whereas the programming of data processing systems evolved into standardized routines and packages of enterprise resource planning (ERP) software [4].Automated college EMS is also a application developed using Mysql and net-beans. Without the help of this software employee management is very difficult. It is hardly possible to find the details of a specific employee from the loads of paper maintained as document [5].

Many EMS have been developed using different technologies, each having different functions and limitations. Performance appraisal is also considered as a key factor in profit and development of the company [6]. This project will help in reducing the limitations of the existing system and making the use of EMS easy.

\section{PROPOSED SYSTEM}

\section{A. Modules in the project}

There are 5 main modules in this project named as Workday, Time-sheet, Leave calculator, Data of Employee and Performance chart.

\section{a. Workday}

Workday is created by the admin for which time-sheet will be filled by employees. Workday name, Category, Day, Month, and Year will be stored in this module. All the workdays created by the admin will be displayed in one place.

\section{b. Time-sheet}

Time-sheet will be filled by the employee for the workdays created by the admin. Employees need to be honest while filling the time-sheet as it will be approved or rejected by the admin. Work hours, Learning hours, Start time, End time, and comments will be stored in this module. All the time-sheets filled by employees will be displayed in one place with the status of the time-sheet. Rejected time-sheets with comments will be displayed at a different place and the employee needs to refill the rejected time-sheet. Admin can approve or reject the time-sheet according to him with comments.

\section{c. Leave Calculator}

Leave taken by the employee will be considered in this module. Using the data of the time-sheet, leaves taken by the employee will be shown on his/her dashboard Compulsory leaves, Weekly off, and Optional off will be calculated and will be displayed on the dashboard of the employee.

\section{d. Data of Employee}

While registering the new employee, the Admin fills the data of the employee which includes the First name, last name, Email id, Date of Birth, Blood group, Department, Band, Mobile Number, Address, and Date of joining. This data can be further used by other departments (Especially by HR for evaluation).

\section{e. Performance Chart}

Performance Charts are created between working hours and learning hours for a particular employee. Using the information the employee can self-evaluate and can observe his/her performance. The admin can also have a watch on employee's performance. 


\section{FLOW OF APPLICATION}

The employee comes to the application and lands on the login page which is the 'index.php', the employee then login into their account and is directed to one of three sections of the website based on their role. If the employee enters the correct credentials the employee lands on the dashboard of their respective section otherwise the user is shown an error message and redirected back to the login page. All the internal features of the application can be accessed after logging into the application. The employee can logout of the application when they want to from any of the internal pages of the application.

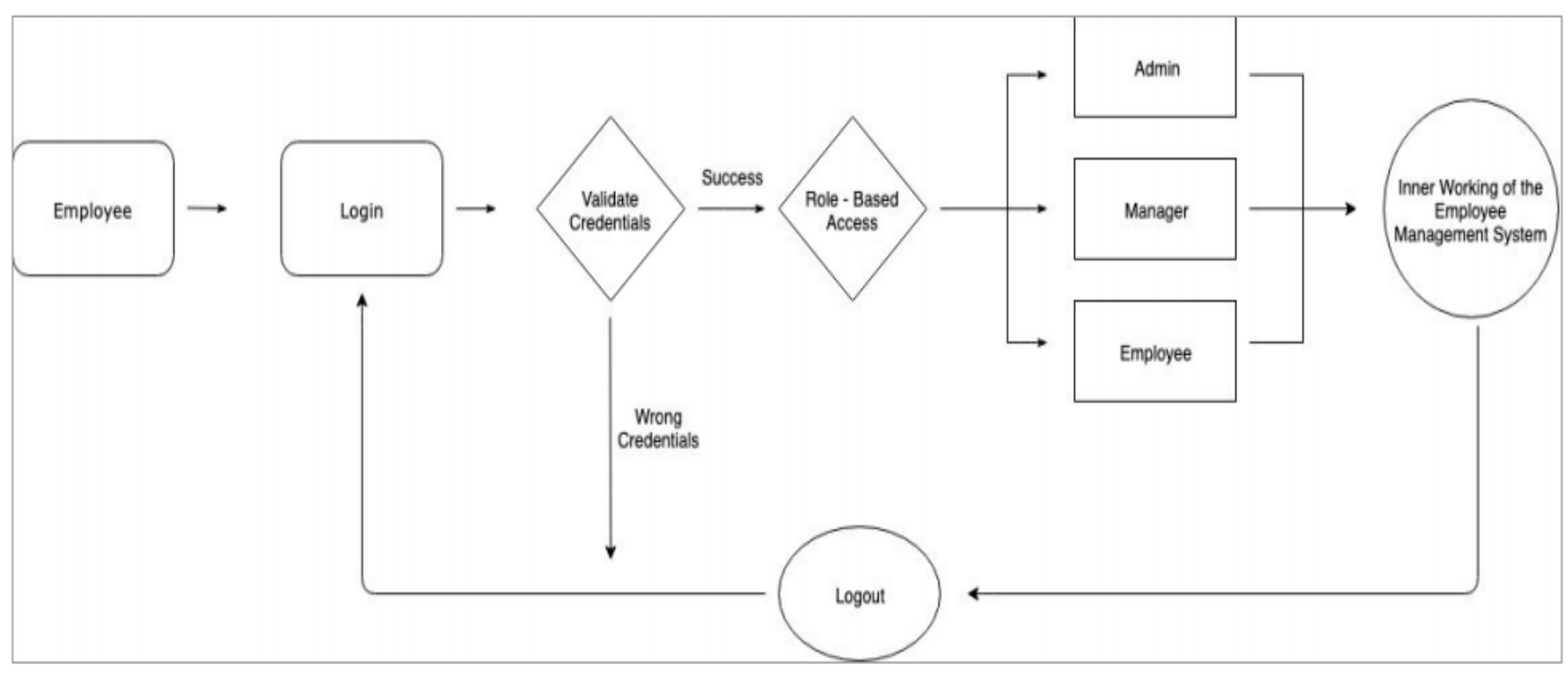

Fig 1: Flow of Application

V. ARCHITECTURE

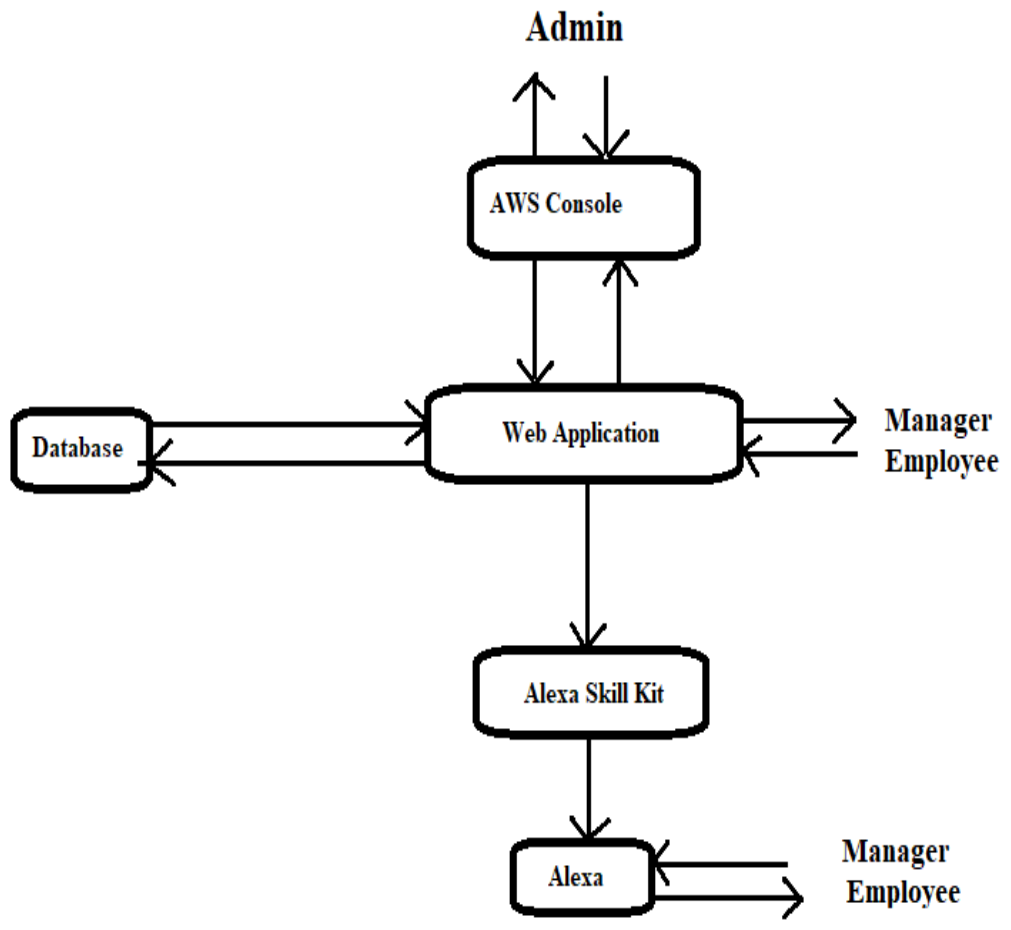

Fig 2: Architecture of the project 


\section{E-R DIAGRAM}

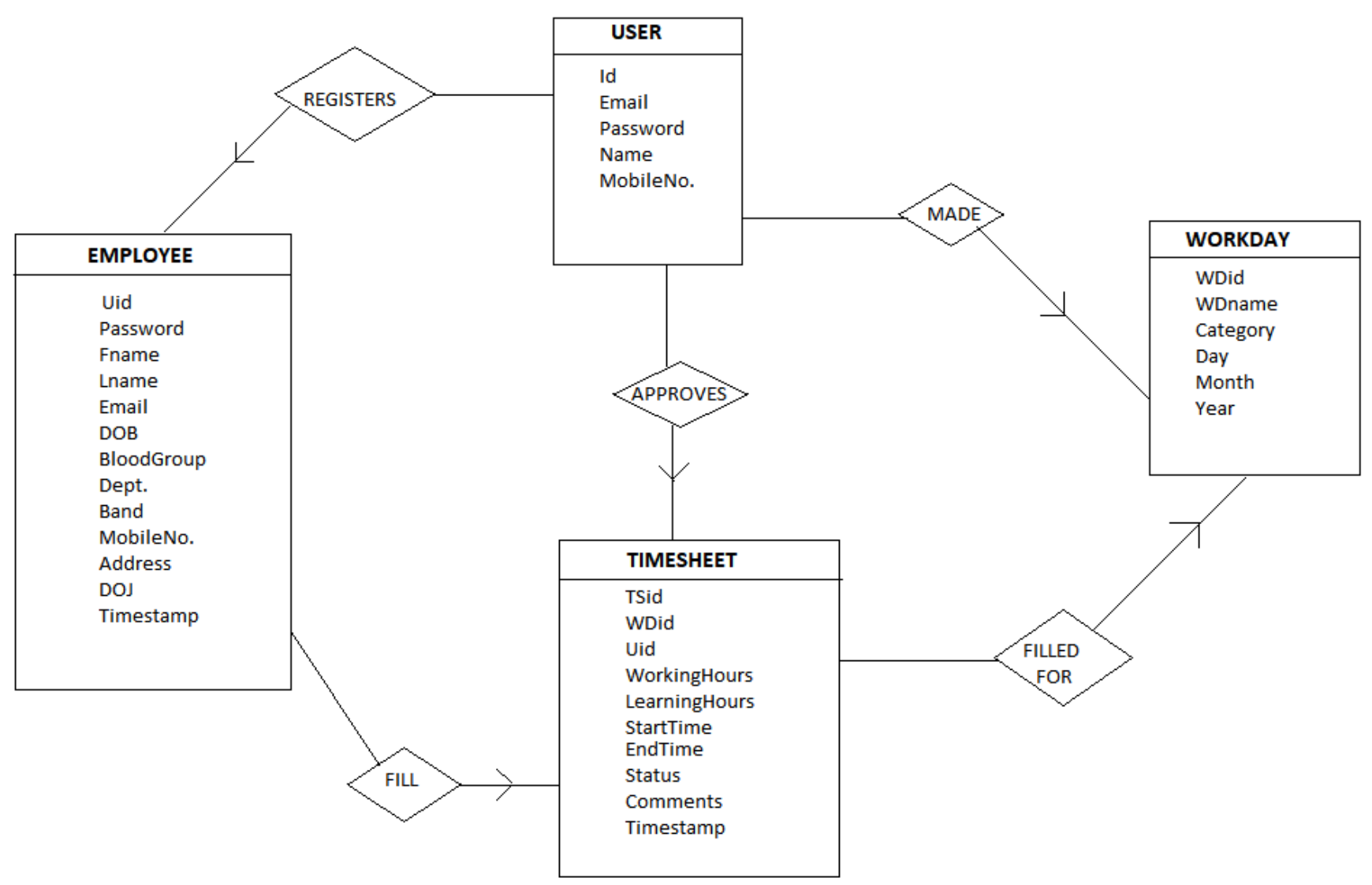

Fig 3: E-R Diagram of project

- User/Admin registers an employee.

- Employee fills Time-sheet.

- Time-sheet is filled for Workday.

- User/Admin creates a Workday.

- User/Admin approves the Time-sheet.

\section{RESULTS}

In this chapter, the result of the project will be discussed.

Figure 4 is the login page of the admin from where it can login into the application by entering the email and password.Their is also a option to login as a employee and a option to create a account for admin. This concept is only for sample project. While implementing such application in real world, the create account option is only accessible to admin or to manager in some cases. There is only 1-2 admin for such application and no. of managers can differ.

Figure 5 is the dashboard of the admin from where he/she can get access to different kind of information of the employee. Options given on the menu bar are described below with the respective functions .Different options or link have different functions. Quick information of different employees is displayed on the dashboard. The table used to show the data can also filter the data according to the need and can also help in searching specific data. "View Time-sheet" will show the time-sheet of the following employee and admin can perform evaluation according to the work. "View performance" option will show the performance of the respective employee.
"LOGOUT" will end the session and will redirect to the login page.

Figure 6 is the add employee option page from where new employee can be added. First name of the employee will be entered in the first field. Last name will store the last name or surname of the employee. Email address using which employee can login into application will be stored in email field. Mobile number which can be used for contact purposes will be stored in mobile no.. Password field will store the password which the admin will assign to the employee for login. This field can be changed by the employee also according to the need. Date of birth will store the date in form of mm/dd/yyyy. After clicking on the blood group option, different blood groups will be shown and the user need to choose the right choice.

Figure 7 shows the time-sheet of a specific employee, View time-sheets will show all the employees and admin can choose the employee for which he wants to see time-sheets. Admin can approve or reject the time-sheet according to the data provided by the employee with a comment.

Figure 8 is the page to create a workday for an organization. Workday name will store the value if the day was holiday or a workday.

Figure 9 will show the performance of the employee summarized by the google charts. Performance chart for each employee can be seen individually by clicking on the respective employee. 
Figure 10 is the dashboard for the employee when it login into the application. Rejected time- sheets which are sent back for editing can be seen on the dashboard. No. Of leaves taken by the employee and their category are also shown on the dashboard.

Figure 11 is the add time-sheet field for the employee where he/she can fill the time-sheet for the the different dates filtered by the month and the year. Working hours, Learning hours, Start time and End time will be filled according to the employee. Comments will contain the details of the work done on the respective workday.

\section{Employee Management System - Admin}

\section{Sign In}

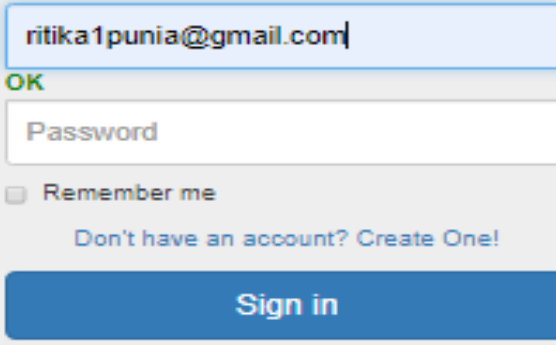

Login as an Employee

Fig 4: Login page of Admin

\section{Employee Management System Home Add Employee View Employee's Workday View Workday View Timesheets Logout}

\section{All Employee's}

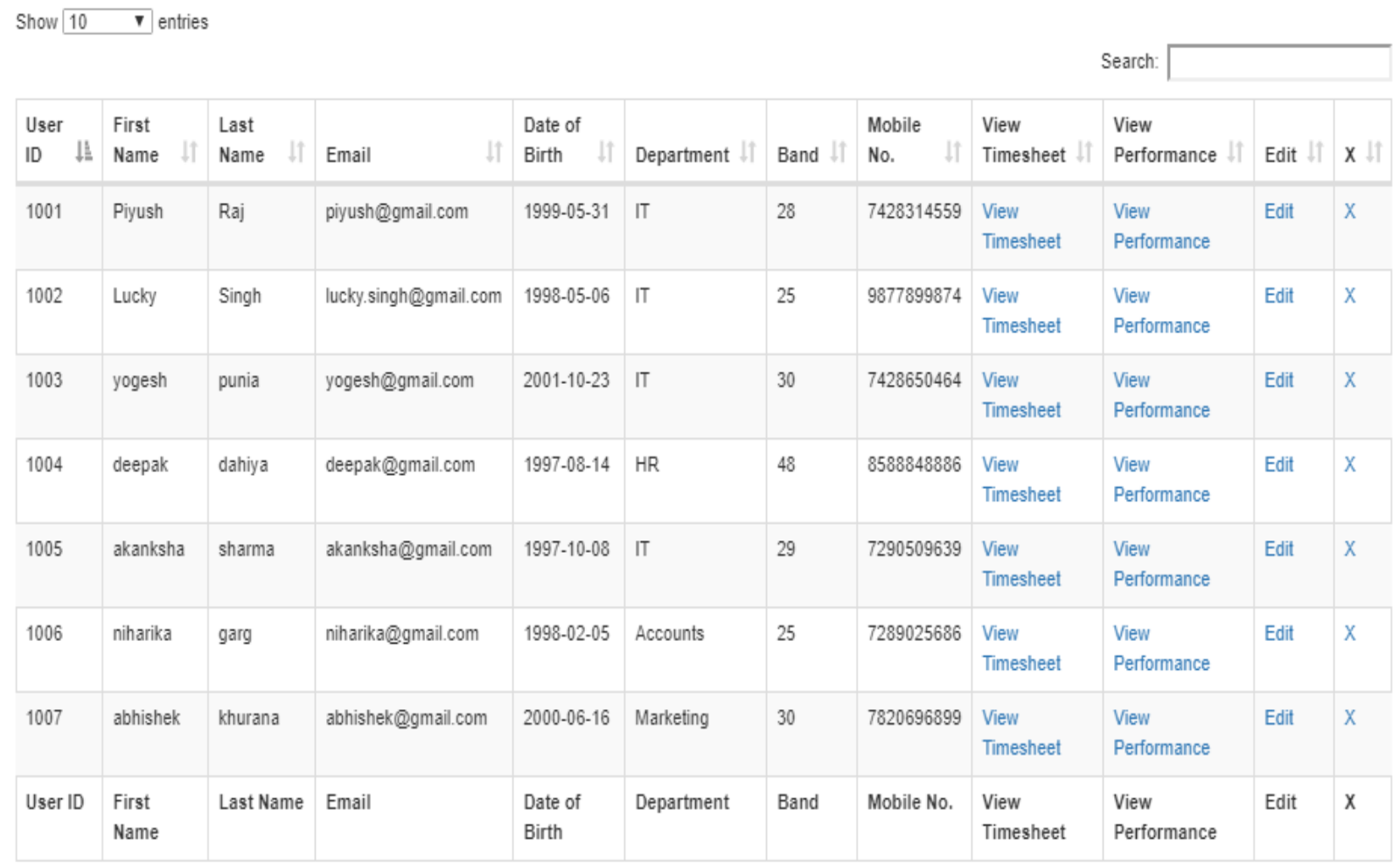




\section{Add Employee}

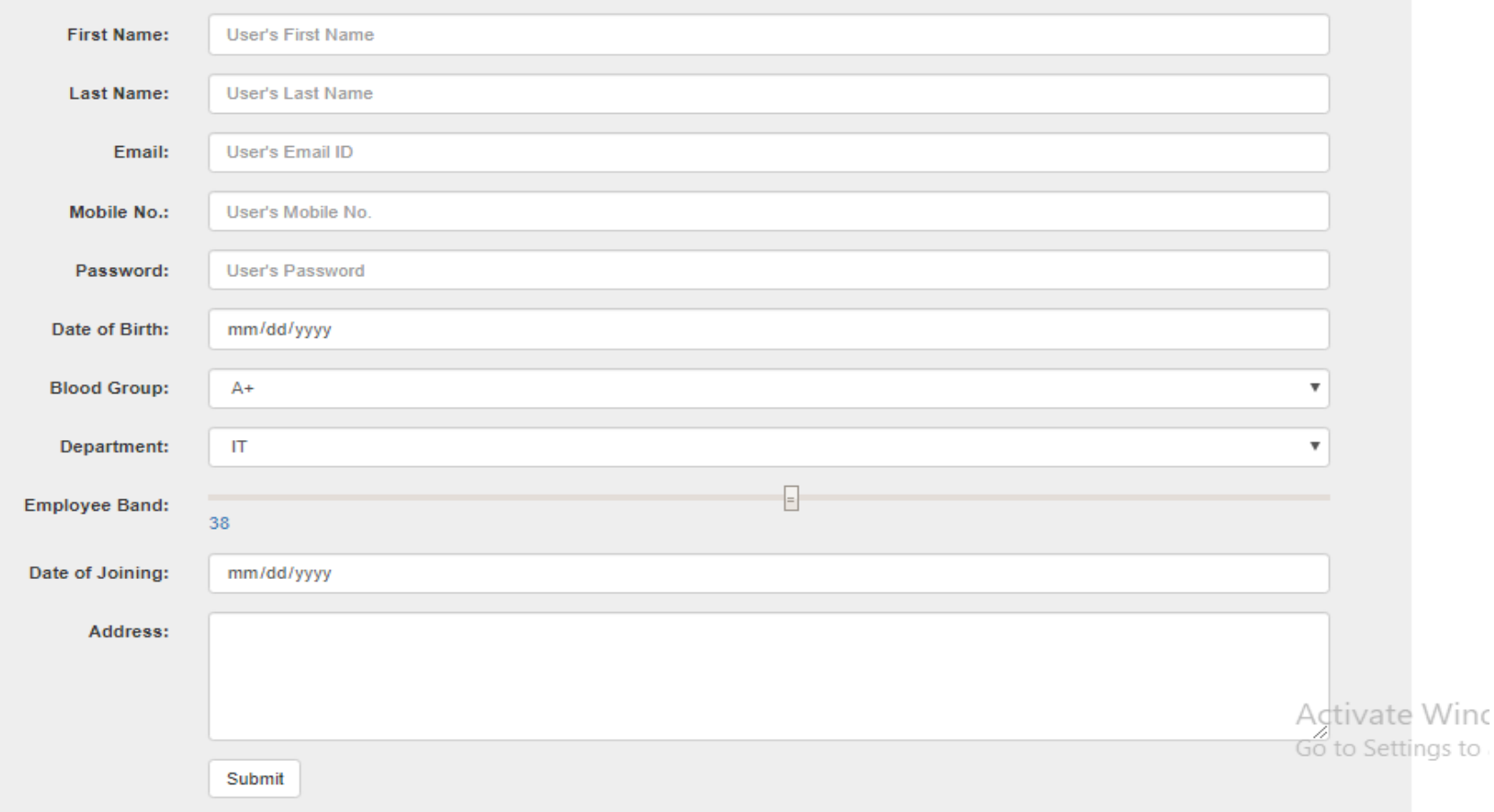

Fig 6: Add Employee page for Admin

\section{Employee Management System Home Add Employee View Employee's Workday View Workday View Timesheets Logout}

\section{View all Timesheet}

\section{Timesheets for Deepak Dahiya}

\begin{tabular}{|c|c|c|c|c|c|c|c|c|c|}
\hline Date & Work Hours & Learning Hours & Start Time & End time & Status & Comments & Approve TS & Reject TS & Add Comments \\
\hline $2 / 4 / 2020$ & 0 & 0 & 0 & 0 & approved & Holiday. & $\checkmark$ & $x$ & $a$ \\
\hline $3 / 4 / 2020$ & 2 & 4 & 9 & 17 & approved & Done!! & $\checkmark$ & $x$ & $a$ \\
\hline $4 / 4 / 2020$ & 2 & 2 & 11 & 16 & approved & Done!! & $\checkmark$ & $x$ & $\Omega$ \\
\hline $5 / 4 / 2020$ & 0 & 0 & 0 & 0 & rejected & Holiday. & $\checkmark$ & $x$ & 2 \\
\hline $6 / 4 / 2020$ & 0 & 0 & 0 & 0 & approved & Holiday. & $\checkmark$ & $x$ & $a$ \\
\hline $7 / 4 / 2020$ & 3 & 4 & 10 & 17 & approved & Done!! & $\checkmark$ & $x$ & $\Omega$ \\
\hline $8 / 4 / 2020$ & 5 & 0 & 9 & 16 & approved & Done!! & $\checkmark$ & $x$ & $\Omega$ \\
\hline $9 / 4 / 2020$ & 5 & 1 & 9 & 19 & in_review & Done!! & $\checkmark$ & $x$ & $a$ \\
\hline $10 / 4 / 2020$ & 0 & 0 & 0 & 0 & in_review & Holiday. & $\checkmark$ & $x$ & $\Omega$ \\
\hline $11 / 4 / 2020$ & 2 & 3 & 10 & 18 & approved & Overtime. & $\checkmark$ & $x$ & $a$ \\
\hline $12 / 4 / 2020$ & 0 & 0 & 0 & 0 & in_review & Holiday & $\checkmark$ & $x$ & $a$ \\
\hline $13 / 4 / 2020$ & 0 & 0 & 0 & 0 & approved & Holiday. & $\checkmark$ & $x$ & $a$ \\
\hline $14 / 4 / 2020$ & 0 & 0 & 0 & 0 & in_review & Holiday & $\checkmark$ & $x$ & $Q$ \\
\hline $16 / 4 / 2020$ & 2 & 3 & 10 & 17 & in_review & Done!! & $\checkmark$ & $x$ & $a$ \\
\hline $17 / 4 / 2020$ & 5 & 0 & 10 & 19 & in_review & Done!! & $\checkmark$ & $x$ & Go to \\
\hline $18 / 4 / 2020$ & 2 & 3 & 10 & 19 & in_review & Overtime. & $\checkmark$ & $x$ & $\Omega$ \\
\hline
\end{tabular}

Fig 7: Time-sheet page for particular employee(Admin side) 
International Journal of Innovative Research in Computer Science \& Technology (IJIRCST)

ISSN: 2347-5552, Volume-8, Issue-3, May 2020

https://doi.org/10.21276/ijircst.2020.8.3.28

www.ijircst.org

\section{Employee Management System Home Add Employee View Employee's Workday View Workday View Timesheets Logout}

\section{Workday}

Workday Name:

Workday Name

Category:

Workday

$\checkmark$

Day:

day

Month:

January

$\checkmark$

Year:

Year

Submit

Fig 8: Create Workday page for Admin

\section{Employee Management System Home Add Employee View Employee's Workday View Workday View Timesheets Logout}

\section{View Employee Performance}

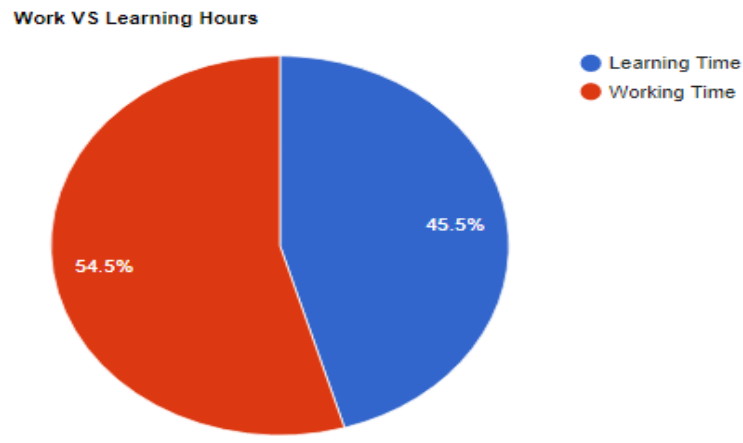

\begin{tabular}{|l|l|l|}
\hline Workday Date & Work Hours & Learning Hours \\
\hline $2 / 4 / 2020$ & 0 & 0 \\
\hline $3 / 4 / 2020$ & 2 & 4 \\
\hline $4 / 4 / 2020$ & 2 & 2 \\
\hline $6 / 4 / 2020$ & 0 & 0 \\
\hline
\end{tabular}

Fig 9: Performance chart of employee accessed by Admin 


\section{View Rejected Timesheets}

Show $10 \quad$ entries



Showing 1 to 1 of 1 entries

\section{Leaves}

\begin{tabular}{llll} 
S No & Date & Category & Workday Name \\
\hline 1 & $2 / 4 / 2020$ & compulsaryoff & Holiday(Ram Navmi) \\
2 & $6 / 4 / 2020$ & compulsaryoff & Holiday(Mahavir Jayanti) \\
3 & $13 / 4 / 2020$ & compulsaryoff & Holiday(Vaisakhi) \\
4 & $1 / 4 / 2020$ & workday & working day \\
5 & $15 / 4 / 2020$ & workday & working day \\
6 & $24 / 4 / 2020$ & workday & working day \\
7 & $6 / 5 / 2020$ & workday & Working Day \\
8 & $12 / 5 / 2020$ & workday & Working Day
\end{tabular}

Total Leaves: 8

Compulsary Leaves: 3

Non-Compulsary Leaves: 5

Fig 10: Employee Dashboard

\section{Employee Management System Home Add Timesheet View Timesheet Performance Chart Logout}

\section{Add Timesheet}

Please fill the Timesheet for: April / 2020



Fig 11: Add Time-sheet page for employee 


\section{CONCLUSION \& FUTURE SCOPE}

The Employee Management System implemented using AWS and PHP, provides a solution to various employees of Birdhouse Shelter. The system is currently successfully running in the organization. The key reasons for the success behind the application is the ease of access, cyber security processes implemented to maintain data security in the application and the portability of accessing the application from any device helps the employees keep the live status update of the work related to their department and take the required action if the work concerned to their department is not done on time. Managing employees becomes easy as the administrator can easily access which employee is managing whom, and what work is being done by what employee on a particular day. The application can be enhanced by adding the feature of sending automatic email alerts to the users about the status of the reports, the current system only send updates via SMS to the users. The system also has the scope of automation of handling of situations in which an attendance module could be added which would note the time of entry and exit of the employee by scanning their faces/ID cards. Using AWS and Alexa is already a step towards using this application more easily and efficiently in their office premises and can easily be scaled if the need arises in the future.

\section{REFERENCES}

[1] Kancho Dimitrov Kanchev,"Employee Management System", MSI Report 06170 Växjö University ISSN 1650-2647, SE-351 95 ISRN VXU/MSI/DA/ E/--06170/--SE, Dec 2006.

[2] Madya Ansari, Maviya Shaikh , Ansari Abdul Basit, Jigna Waghela,'Employee Manage ment System", Published in International Journal of Scientific \& Engineering Research Volume 9, Issue 2, February-2018

[3] P.U Singh, Hemant Singh,Khan Abdul Ahad Zubair,Professor Akshata Laddha,'Employee Management System",Published in International Research Journal of Engineering and Technology,May 2019.

[4] Mweemba Simaanya,"Employee Management System", Thesis, The University of Zambi- a School of Natural Sciences, Department of Computer Studies, 2014.

[5] Employee Management System. Available: http://www.123seminarsonly.com/Seminar-

Reports/039/89606104-College-Employee-Manageme nt-System.docx

[6] Sadhana J. Kamatkar, Amarapali Tayade, Amelec Viloria, and Ana Hernandez-Chachin, "Application of classification technique of data Mining for employee Management Syst- em", Published in Springer International Publishing AG, part of Springer Nature 2018, Y. Tan et al. (Eds.): DMBD 2018, LNCS 10943, pp. 434-444, 2018. 